\title{
SATELLITE OBSERVATIONS OF URBAN GREENERY PHENOLOGY IN DOWNTOWN BEIJING AT METER TO KILOMETER SCALES
}

\author{
Hexiang Wang ${ }^{1}$, Zhao-Cheng Zeng ${ }^{2}$ \\ ${ }^{1}$ Department of Landscape Architecture, University of Washington, Seattle, WA, USA \\ ${ }^{2}$ Division of Geological and Planetary Sciences, California Institute of Technology, Pasadena, CA, USA
}

\begin{abstract}
To precisely describe the dynamics of vegetation cover in high-density urban areas, this study evaluates the spatial and temporal consistency of the Normalized Difference Vegetation Index (NDVI) from multiple satellite data sources. The study areas of Downtown Beijing target at two scales: the district scale, and the neighborhood scale. Results show that Planet, Sentinel-2, Landsat-8, and MODIS share a similar spatial pattern; Sentinel-2, Landsat-8, and MODIS correlate in the temporal change of NDVI at both spatial scales in 2019, but AVHRR does not present useful information of spatial patterns of urban green space or urban vegetation dynamics at these two scales. Seasonal contrast derived from Sentinel- 2 and Landsat- 8 can be visualized through seasonal variation ratio to assist urban green space planning. This study highlights the usefulness of existing satellite observations in monitoring a variety of urban greening typologies at the neighborhood scale for improving urban environmental planning.
\end{abstract}

Index Terms - Urban greenery, Satellite observations, NDVI, Beijing

\section{INTRODUCTION}

Urban greenery provides diverse ecosystem services [1], including modifying microclimate [2][3], framing multimodal social functions [4], conserving habitat and biodiversity [5], improving human well-being [6], and promoting street aesthetics [7]. Downtown neighborhoods of many big cities face problems related to deficient greening, and conflicts exist between large-scale urban green space planning and urban built-up area development. To balance the tradeoff, a rising trend of green street creation [8] in relatively denser urban neighborhoods is one strategy to maximize green coverage in limited space.

Satellite observation is an effective and timely way of monitoring terrestrial greenery by using various vegetation indices including NDVI. For example, previous study conducted by Wu et al. [3] adopted NDVI as one of the seven parameters to investigate urban thermal environment; Wang et al. [9] did correlation analysis of NDVI and proportion index of green space area; $\mathrm{Li}$ et al. [7] analyzed correlation and the spatial difference between green view index and NDVI.

As more satellite data at meter to kilometer scales become publicly available, two questions remain to be answered: (1) Are the NDVI data product at different scales sensitive to the spatial and temporal variabilities of urban greenery; (2) Are they consistent in monitoring urban greenery, such as the phenology of urban trees?

To address these two questions, we collected NDVI data from five satellites and used Downtown Beijing as our case study area. As a megacity located in northern China, the overall population of Beijing Municipality is over $21,890,000$ in 2020. The heatwave in Beijing has been proven to be a threat to local residents [10], and air pollutants including PM2.5 threaten public health of local residents [11]. These environmental issues require more efforts to choose proper tree species and construct green streets for heat island mitigation and pollution control. To deal with environmental issues, the city government has developed multiple policies to facilitate the expansion of green space after 2001 [12]. The preparation for the Beijing 2008 Olympics accelerated green space planning and construction processes of the city [13]. Starting from 2021, the "14th FiveYear" Plan of Beijing proposed by Beijing Municipal Commission of Development and Reform requires a systematic increase of urban ecological capacity, including the overall forest cover rate of $45 \%$, the forest cover rate of $32 \%$ in plain areas, and the area within 500-meter park service distance reaching to $90 \%$ [14]. In this context, quantifying ecosystem services of street trees in the urban environment may facilitate precise decision-making of urban environmental planning.

\section{METHOD}

\subsection{Datasets}

There are five sources of NDVI data for comparisons: 1) 3 $\mathrm{m}$ resolution Planet NDVI, 2) $10 \mathrm{~m}$ resolution Sentinel-2 Level-2A, 3) $30 \mathrm{~m}$ resolution Landsat-8 Collection 1 Tier 1 8-Day NDVI Composite, 4) The Terra Moderate Resolution Imaging Spectroradiometer (MODIS) Vegetation Indices (MOD13Q1.006) Version 6 16-Day Global 250m, and 5) 5 km resolution Advanced Very High Resolution Radiometer (AVHRR) Land NDVI (Table 1). 
Table 1. NDVI datasets used in this study.

\begin{tabular}{llll}
\hline Satellites & $\begin{array}{l}\text { Spatial } \\
\text { resolution }\end{array}$ & $\begin{array}{l}\text { Temporal } \\
\text { resolution }\end{array}$ & Data source \\
\hline Planet & $3 \mathrm{~m}$ & Almost daily & www.planet.com \\
Sentinel-2 & $10 \mathrm{~m}$ & 5 days & GEE \\
Landsat-8 & $30 \mathrm{~m}$ & 16 days & GEE \\
MODIS & $250 \mathrm{~m}$ & 8 days & GEE \\
AVHRR & $\sim 5 \mathrm{~km}$ & Daily & NOAA \\
\hline
\end{tabular}

GEE - Google Earth Engine; NOAA - National Oceanic and Atmospheric Administration

\subsection{Study areas}

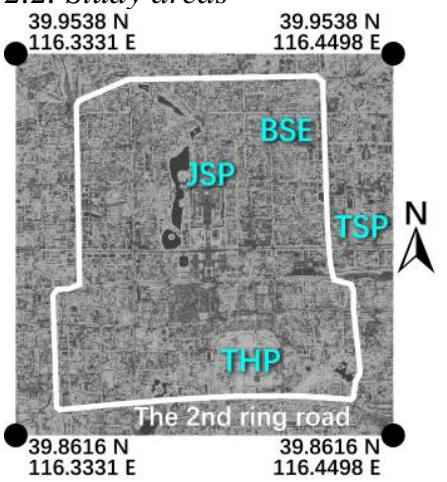

Figure 1. District-scale study areas around the 2 nd ring road of Beijing; neighborhood-scale study areas: Temple of Heaven Park (THP), Temple of Sun Park (TSP), JingShan Park (JSP), and the block in Beixinqiao SouthEast (BSE); base map from Sentinel-2

Being smaller than some previous studies investigating Beijing [3][7][9], the core urban area enclosed by and around the 2 nd ring road of Beijing as the district-scale study area. Acknowledging that understanding spatial and temporal scales is necessary to comprehend urban ecological systems [1], four smaller rectangular study areas are defined at the neighborhood scale within the district-scale study area concentrating on urban parks of different sizes and involving greenery embedded in urban street and alleyway grids. These neighborhood-scale study areas are Temple of Heaven Park (THP), Temple of Sun Park (TSP), JingShan Park (JSP), and the block in Beixinqiao SouthEast (BSE). THP and JSP are primarily composed of historic parks. TSP is a combination of a historic park and surrounding neighborhoods. BSE is a residential block with scarce vegetation cover. Boundaries used for data analysis slightly vary with available pixels in each dataset.

\subsection{Temporal scale}

The temporal scale of this study is in the period from January 1st, 2019 to December 31st, 2019, a one-year growing cycle of the urban vegetation. Within this study period, the availability of each dataset varies, depending upon data availability, temporal resolution, and cloud exclusion.

\section{RESULTS AND DISCUSSIONS}

\subsection{Spatial pattern of NDVI}

As shown in Figure 2, five satellite NDVI datasets show clear contrasts in terms of spatial resolution of NDVI in the district-scale study area. THP in the south is the largest green patch in this area, followed by a cluster of green spac- es in the southeast, Taoranting Park in the south, TSP to the east, JSP on the central axis, and other green spaces and the canopy along streets. The Planet satellite images on May 28th present a comparatively higher NDVI in the whole study area including built-up areas and water bodies (Figure 2a). As a high spatial resolution satellite, Planet shows clear boundaries and shapes of street trees and tree clusters; for instance, around the East entrance of Taoranting Park (ETP), subtle spatial variation of NDVI can be observed, but the waterbody appears to be similar to other built-up areas (Figure 2b). The Sentinel-2 dataset has a comparatively lower spatial resolution, but the vegetation distribution can also be observed at the street level with fewer details; furthermore, the overall NDVI of the study area of Sentinel2 is lower than that of Planet on the same day (Figure 2c). The Landsat- 8 dataset on May 25th also has the capacity to clearly identify urban parks and other major vegetation covers and features, but this dataset loses more details of the street-level vegetations due to a lower spatial resolution (Figure 2d). The MODIS dataset presents a comparatively blurry image where only locations of large urban green spaces can be perceived, for example, THP, CSE, and TSP, while other landscape features including large water bodies are not visible at this scale (Figure 2e). The $4 * 4$ pixel AVHRR dataset only indicates a higher NDVI value in the southeast and the northeast, and no landscape features can be mapped out (Figure 2f).

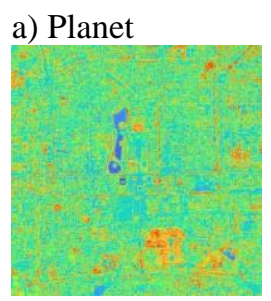

(d) Landsat-8

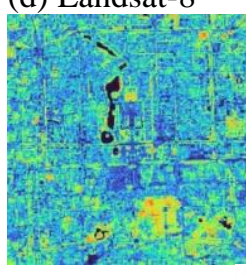

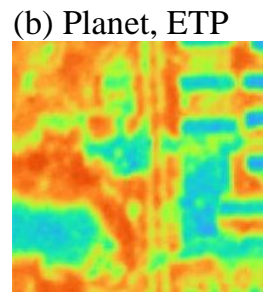

(e) MODIS (c) Sentinel-2

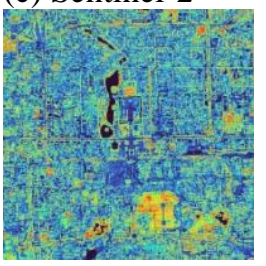

(f) AVHRR

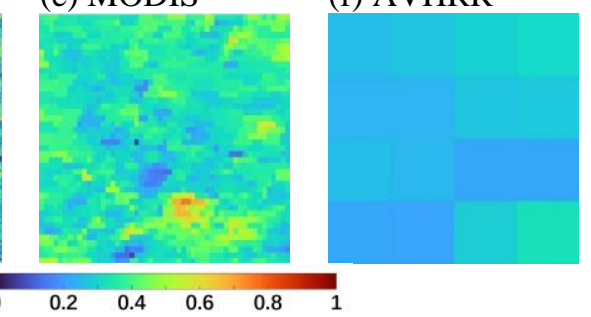

Figure 2. Examples of satellite observed NDVI in Downtown Beijing from different satellites. ETP - the East entrance of Taoranting Park

\subsection{Seasonal cycle of NDVI}

Within the general study area, seasonal cycles of mean NDVI from four datasets are presented in Figure 3. Sentinel2, Landsat-8, and MODIS datasets consistently depict a rapid vegetation growth between Julian days 81 and 129. Approximately starting from Julian day 130, these three datasets show relatively stable trends for about three months, and later on, a steep slope of greenery fading starts from Julian day 288. Daily AVHRR NDVI fluctuates sharply. To 
reveal the general trend of daily AVHRR, the first attempt is to calculate a Gaussian Process Regression (GPR) model; in another attempt, referring to the available days of Sentinel2, 58 Scattered Points (SP) are filtered out for comparison. However, AVHRR GPR has a vague and obscure correlation to the other three datasets, and AVHRR SP also has little similarity to Sentinel-2, even though the SP is mostly on days that are not cloudy. Correlation analysis concentrates on Sentinel-2, Landsat-8, and MODIS datasets. NDVI data are categorized into monthly means. Sentinel-2, Landsat-8, and MODIS have 12, 9, and 12 monthly means, respectively, depending on data availability. When involving Landsat- 8 monthly means, the peer dataset drops monthly means of February, April, and July to keep the numbers of monthly means on both sides balanced. Three Linear Regression Relations between every two datasets show strong similarity. The Pearson Correlation Coefficients are 0.9547, 0.9701, 0.9395, between 1) Sentinel-2 and Landsat-8, 2) Landsat-8 and MODIS, and 3) MODIS and Sentinel-2, respectively; the p-values are all smaller than 0.01 .

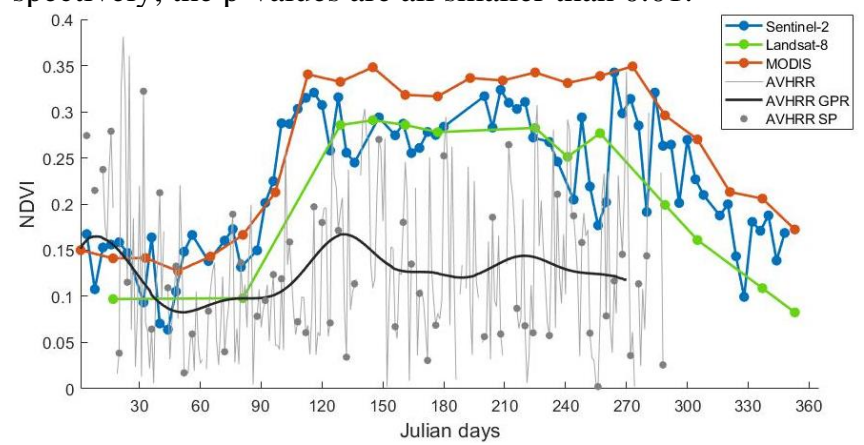

Figure 3. Time series of averaged NDVI over the study area from four satellites: Sentinel-2, Landsat-8, MODIS, and AVHRR. Gaussian Process Regression (GPR) applied to AVHRR data to obtain the black curve; Scattered Points (SP) of AVHRR filtered out referring to Sentinel-2

\subsection{Seasonal contrast of NDVI between summer and winter}

Seasonality is usually an important factor in urban landscape planning and design. In Figure 4, we compared Sentinel-2 and Landsat- 8 datasets in regard to the winter-summer variation. In this section, two winter days and two summer days are selected to compose an example. Within the districtscale study area, the mean value of NDVI of Sentinel-2 is 0.1586 on January 20th, and 0.2838 on June 29th; the mean seasonal variation ratio $\left(\mathrm{SVR}=\mathrm{NDVI}_{\text {summer }} / \mathrm{NDVI}_{\text {winter }}\right)$ of the selected days is 1.7895; the mean value of NDVI of Landsat- 8 is 0.0970 on January 17 th, and 0.2779 on June 26th; the mean SVR of the selected days is 2.8660. The seasonal contrasts represented by mean SVR are almost the same in Sentinel- 2 and Landsat- 8 datasets in this case. On January 20th, the SD of NDVI of Sentinel-2 is 0.1147 ; on January 17 th, the SD of NDVI of Landsat-8 is 0.0796 . On June 29th, the SD of NDVI of Sentinel-2 is 0.2141; on June 26 th, the SD of NDVI of Landsat- 8 is 0.1505 . Therefore, on selected winter and summer days, Sentinel-2 always has a greater pixel contrast of NDVI than Landsat- 8 within the study area. SVR can be visualized spatially (Figure 4a, 4b), and inform distributions of evergreen and deciduous trees, supporting urban environmental planning that takes seasonality into consideration. However, it is necessary to acknowledge the existence of deviations. For example, the Sentinel-2 dataset is quite sensitive to disturbance, especially between Julian days 270 and 300 (Figure 3). Therefore, we recommend that monthly mean NDVI be applied when urban planners do an environmental analysis of the status quo. (a) Sentinel-2, SVR

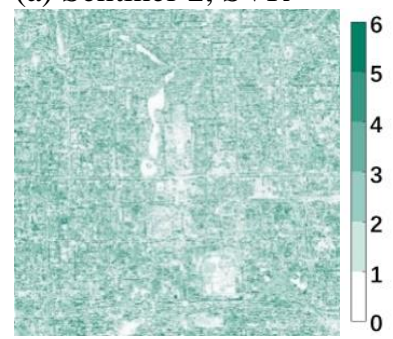

(b) Landsat-8, SVR

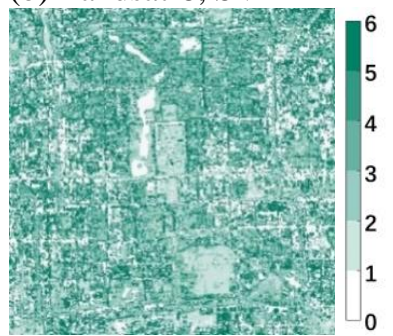

Figure 4. Seasonal variation ratio (SVR) derived as the ratio of NDVIs between summer and winter.

\subsection{Spatial and temporal variabilities of NDVI at the neigh- borhood scale}

A large portion of urban planning and landscape architecture projects are focused on the neighborhood scale. Thus, THP, TSP, JSP, and BSE are defined within the general study area to test correlations among Sentinel-2, Landsat-8, and MODIS, as shown in Figure 5. These four sites contain distinct attributes in terms of annual life cycles (being evergreen or deciduous) percentage of land covered by canopy or ground vegetations (Figure $4 \mathrm{a}, 4 \mathrm{c}, 4 \mathrm{e}, 4 \mathrm{~g}$ ). The result shows that though the site conditions vary, strong correlations can be perceived in the seasonal variation (SV) of each site (Figure 4b, 4d. 4f, 4h). Surprisingly, $250 \mathrm{~m}$ resolution MODIS NDVI still has the capacity to describe the SV of vegetation at the neighborhood scale without completely dissolving in the surrounding environment.

\section{CONCLUSIONS}

Planet, Sentinel-2, Landsat-8, and MODIS show identical NDVI spatial patterns, while the spatial resolution of AVHRR is not high enough to depict urban landscape features. Monthly means of NDVI prove that SV of NDVI from Sentinel-2, Landsat-8, and MODIS datasets has strong correlations at the district scale, and SV of NDVI from these three datasets is also identical at the neighborhood scale, while AVHRR does not precisely track district level vegetation change over time. Relying on high spatial resolution and data availability, Sentinel- 2 and Landsat- 8 can be mutually complementary datasets to visualize the spatial pattern of SVR of urban vegetations; replacing daily NDVI data with monthly mean NDVI of these two datasets may improve the validity of SVR calculation. Future studies can 
(a) THP, NDVI

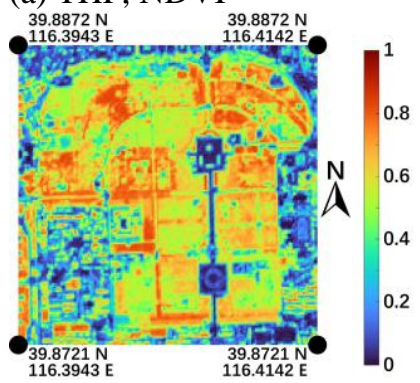

(e) JSP, NDVI

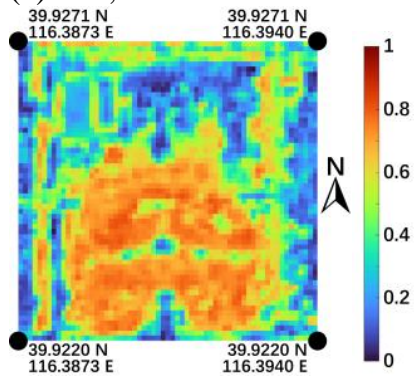

(b) THP, SV

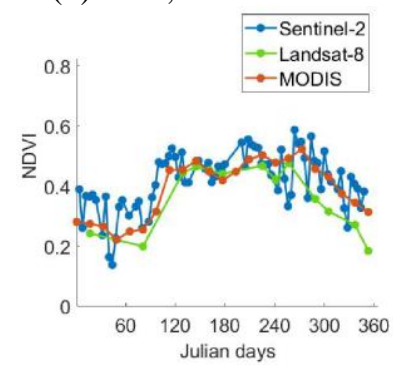

(f) JSP, SV

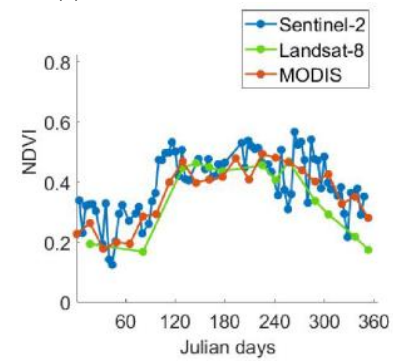

(c) TSP, NDVI

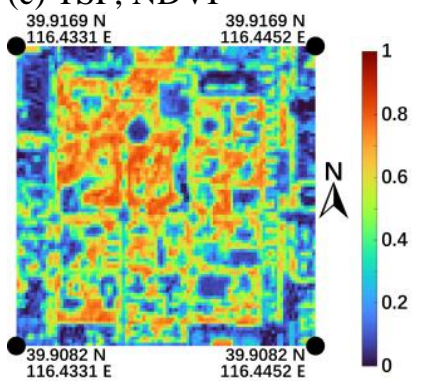

(g) BSE, NDVI

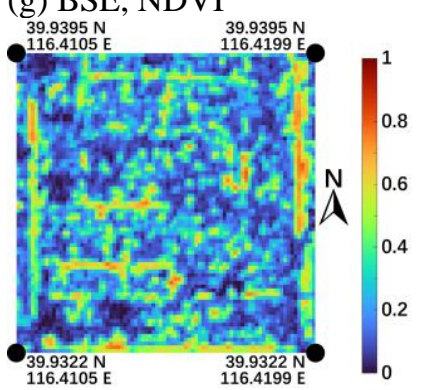

(d) TSP, SV

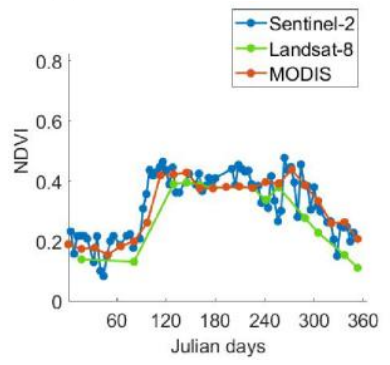

(h) BSE, SV

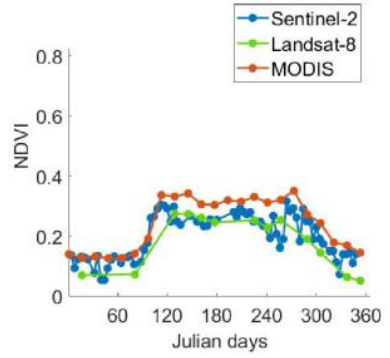

Figure 5. Spatial patterns and temporal variabilities of NDVIs at the neighborhood scale from Sentinel-2, Landsat-8, and MODIS. Data from four neighborhoods shown in Figure 1 are demonstrated here.

quantify to what extent does the validity increase. Neighborhood-scale Sentinel-2, Landsat-8, and MODIS NDVI are eligible to monitor a variety of urban greening typologies, e.g., growth and succession of street trees, green roofs, and urban prairies/grasslands. Planet NDVI can assist with schematic landscape and urban design by clearly outlining shapes of greenery.

\section{ACKNOWLEDGEMENT}

We thank Planet company for providing high-resolution satellite NDVI data, Google Earth Engine for providing Sentinel-2, Landsat-8, MODIS NDVI data, and NOAA for providing AVHRR NDVI data.

\section{REFERENCES}

[1] Rottle, N., \& Yocom, Kenneth. (2010). Ecological design (The AVA series). Lausanne, Switzerland : La Vergne, TN: AVA Publishing ; Distributed in the USA \& Canada by Ingram Publisher Services.

[2] Erell, E. (2017). Urban Greening and Microclimate Modification. In Greening Cities (Advances in 21st Century Human Settlements, pp. 73-93). Singapore: Springer Singapore.

[3] Wu, Z., Yao, L., \& Ren, Y. (2020). Characterizing the spatial heterogeneity and controlling factors of land surface temperature clusters: A case study in Beijing. Building and Environment, 169, 106598.

[4] Hou, J. (2017). Urban Community Gardens as Multimodal Social Spaces. In Greening Cities (Advances in 21st Century Human Settlements, pp. 113-130). Singapore: Springer Singapore.

[5] Werner, P., \& Kelcey, J. (2017). Urban Green and Biodiversity. In Greening Cities (Advances in 21st Century Human Settlements, pp. 131-154). Singapore: Springer Singapore.

[6] Reyes-Riveros, R., Altamirano, A., De La Barrera, F., Rozas-
Vásquez, D., Vieli, L., \& Meli, P. (2021). Linking public urban green spaces and human well-being: A systematic review. Urban Forestry \& Urban Greening, 61, 127105.

[7] Li, T., Zheng, X., Wu, J., Zhang, Y., Fu, X., \& Deng, H. (2021). Spatial relationship between green view index and normalized differential vegetation index within the Sixth Ring Road of Beijing. Urban Forestry \& Urban Greening, 62, 127153.

[8] Dover, V., \& Massengale, John. (2014). Street design : The secret to great cities and towns. Hoboken, New Jersey: John Wiley $\&$ Sons.

[9] Wang, H., Hu, Y., Tang, L., \& Zhuo, Q. (2020). Distribution of Urban Blue and Green Space in Beijing and Its Influence Factors. Sustainability (Basel, Switzerland), 12(6), 2252.

[10] Yin, Q., \& Wang, J. (2017). The association between consecutive days' heat wave and cardiovascular disease mortality in Beijing, China. BMC Public Health, 17(1), 223.

[11] Maji, K., Li, V., \& Lam, J. (2020). Effects of China's current Air Pollution Prevention and Control Action Plan on air pollution patterns, health risks and mortalities in Beijing 2014-2018. Chemosphere (Oxford), 260, 127572.

[12] Naeem, S., Cao, C., Fatima, K., Najmuddin, O., \& Acharya, B. (2018). Landscape Greening Policies-based Land Use/Land Cover Simulation for Beijing and Islamabad-An Implication of Sustainable Urban Ecosystems. Sustainability (Basel, Switzerland), 10(4), 1049.

[13] Mol, A. (2010). Sustainability as global attractor: The greening of the 2008 Beijing Olympics. Global Networks (Oxford), 10(4), 510-528.

[14] Beijing Municipal Commission of Development and Reform. (2021, April 1). Beijing's 14th Five-Year Plan for National Economic and Social Development and Outline of Long-term Goals for 2035. Retrieved November 29, 2021, from http://fgw.beijing.gov.cn/fgwzwgk/ghjh/wngh/ssiwsq/202104/t202 10401_2341992.htm 